\title{
Modelling of shear behaviour of interfaces involving smooth geomembrane and nonwoven geotextile under static and dynamic loading conditions
}

\author{
Piyush Punetha ${ }^{1}$, Manojit Samanta ${ }^{2 \text { T }}$ \\ 1 Research Scholar, School of Civil and Environmental Engineering, University of \\ Technology Sydney, Sydney 2007, Australia, Email: punetha.piyush@ yahoo.in. ORCiD: \\ 0000-0002-0812-4708 \\ ${ }^{2}$ Senior Scientist, Geotechnical Engineering Group, CSIR-Central Building Research \\ Institute, Roorkee, Uttarakhand, India. Email: manojit@cbri.res.in ORCiD: 0000-0002- \\ $6017-725 X$
}

\footnotetext{
${ }^{\mp}$ Corresponding author: Manojit Samanta, Scientist, Geotechnical Engineering Division, CSIR-Central Building Research Institute, Roorkee, Uttarakhand, India. Email: manojit@cbri.res.in, manojit_samanta@ rediffmail.com Phone: (+91)1332283303
} 


\title{
Modelling of shear behaviour of interfaces involving smooth geomembrane and nonwoven geotextile under static and dynamic
}

\section{loading conditions}

\begin{abstract}
The constitutive modelling of geosynthetic-geosynthetic interfaces is essential to predict the performance of the engineering structures such as landfills, flood control dykes and geotextile encapsulated-sand systems for the protection of shore. This article presents a model to simulate the shear stress/force-displacement behaviour of the interfaces involving smooth geomembrane and nonwoven geotextile under static and dynamic loading conditions. The model is the extension of an existing model developed for predicting the soil-structure interface shear behaviour under static loading conditions. The model is capable of predicting the non-linear pre-peak and the post-peak strain softening/hardening behaviour of the interfaces observed during the laboratory testing. The shear stress/force-displacement response of the interfaces has been modelled by dividing it into three parts: pre-peak, peak and post-peak behaviour. Subsequently, the modelling parameters have been obtained using the results from the laboratory direct shear tests and fixed block type shake table tests conducted on these interfaces. Finally, the modelling parameters have been used to obtain the back-fitted shear stress/forcedisplacement response of the interfaces (which is compared with the experimental results). The predicted shear stress/force-displacement response of the interfaces is found to be in good agreement with the experimental data for both static and dynamic loading conditions.
\end{abstract}

Keywords: Geosynthetics; Interface behaviour; Modelling; Dynamic loading. 


\section{Introduction}

The geosynthetic-geosynthetic interface shear behaviour plays a crucial role in the design of geotechnical engineering structures such as landfills, flood control dykes and geotextile encapsulated-sand systems for the protection of shore (Bergado et al. 2006; Lohani et al. 2006; Krahn et al. 2007; Mariappan et al. 2011; Moreira et al. 2013, 2016; Guo and Chu 2016). The geosynthetic-geosynthetic interface [involving smooth geomembrane (GMB) and geotextile (GTX)] usually acts as a weak zone in these structures due to very low interface shear strength (with interface friction angles ranging between $5-20^{\circ}$ ). However, on the contrary, the low interface shear strength might prove beneficial in some cases. The studies by Hushmand and Martin (1991), Kavazanjian et al. (1991), Yegian and Lahlaf (1992), Yegian and Kadakal (1998, 2004), Yegian and Catan (2004) and Georgarakos et al. (2005) have explored the use of these low friction geosynthetic-geosynthetic interfaces in achieving seismic isolation. Therefore, it is imperative to understand the shear behaviour of the different interfaces involving geosynthetics.

Numerous experimental investigations have been conducted in the past to study the behaviour of geosynthetic-geosynthetic interfaces under static as well as dynamic loading conditions (e.g. Bacas et al. 2011, 2015; Stark et al. 2015; Punetha et al. 2019). Furthermore, a significant amount of work has been reported on the constitutive modelling of geosynthetic-geosynthetic interfaces under static loading conditions, however, in contrast, very little has been reported regarding the constitutive modelling under cyclic or dynamic loading condition (Gilbert and Byrne 1996; Reddy et al. 1996; Esterhuizen et al. 2001; Seo et al. 2003; Liu and Ling 2006; Bacas et al. 2011; Arab et al. 2012). The constitutive modelling of the geosynthetic-geosynthetic interfaces is very 
important to predict the response of the structures involving geosynthetic-geosynthetic interface and assess their long-term performance.

In the present article, an attempt has been made to simulate the shear stress/forcedisplacement response of the GMB-GTX, GMB-GMB and GTX-GTX interfaces under both static as well as dynamic loading conditions. The model used in the present study is an extension of a model originally developed for predicting the soil-structure interface shear behaviour under static loading conditions. Initially, large size direct shear box tests and fixed block type shake table tests have been conducted on GMB-GTX, GMB-GMB and GTX-GTX interfaces. Subsequently, the results of the experimental investigation have been used to derive the modelling parameters. Finally, the back-fitted shear stress/force-displacement response of the interfaces is obtained using the modelling parameters, and the response is compared with the experimental results. The present study on GMB-GTX, GMB-GMB and GTX-GTX interfaces is essential for the design and prediction of long-term performance of landfills, flood control dykes and geotextile encapsulated-sand systems for the protection of shore.

\section{Experimental Study}

\subsection{Materials Used}

Two types of geosynthetics have been used in the present study, nonwoven needlepunched geotextile and smooth High Density Poly Ethylene (HDPE) geomembrane. Tables 1 and 2 show the properties of the geotextile and geomembrane, respectively. Both geotextile and geomembrane are $1.5 \mathrm{~mm}$ thick. The geotextile is made up of polypropylene staple fibres and has a mass per unit area, apparent opening size $\left(O_{95}\right)$ and wide-width tensile strength of $200 \mathrm{~g} / \mathrm{m}^{2}, 0.085 \mathrm{~mm}$ and $14 \mathrm{kN} / \mathrm{m}$, respectively. The geomembrane possesses a density and yield strength of $940 \mathrm{~kg} / \mathrm{m}^{3}$ and $25 \mathrm{kN} / \mathrm{m}$, respectively. 


\subsection{Static Interface Shear Test}

\subsubsection{Test Apparatus and Procedure}

The static interface shear tests have been conducted using a large size direct shear box with $300 \mathrm{~mm} \times 300 \mathrm{~mm}$ plan dimensions. The dimensions of the direct shear box meet the minimum requirements specified in ASTM D5321 (ASTM, 2014). Several researchers have employed direct shear tests to study the interface behaviour of geosynthetics with other materials owing to the simplicity and economy (e.g. Lopes and Silvano, 2010; Punetha et al. 2016, 2017; Punetha and Samanta 2017). Fig. 1 shows the schematic diagram of the large size direct shear box test assembly. The shear box comprises two halves of the same size with fixed upper half, while the lower half is movable. A rigid block is placed in the lower half to prevent the sagging of geosynthetics during the shear test. One geosynthetic is attached to the top of this block while the other geosynthetic is attached to a steel plate $(300 \mathrm{~mm} \times 300 \mathrm{~mm} \times 5 \mathrm{~mm})$, placed at the bottom portion of the upper half. The remaining portion of the upper half is backfilled using sand. A pressure pad is then placed on the top of the backfilled sand. Subsequently, the desired normal load is applied using a loading yoke which rests on the top of the pressure pad. The driving unit generates the horizontal movement in the lower half of the shear box while the motion of the upper half is prevented using a reaction wall. A proving ring is placed between the upper half and the reaction wall to monitor the shear force. Moreover, the horizontal displacement of the box is recorded using a dial gauge.

The geosynthetic specimens are sampled as per ASTM D4354 (ASTM, 2012). The size of the geomembrane and geotextile specimens is $300 \mathrm{~mm} \times 300 \mathrm{~mm}$ and 500 $\mathrm{mm} \times 300 \mathrm{~mm}$, respectively. To prevent slippage during the tests, the geomembrane specimens are firmly glued to the rigid block/ steel plate, while the edges of geotextile specimens are clamped. All the tests have been performed under a constant shearing rate 
of $0.314 \mathrm{~mm} / \mathrm{min}$ and over a normal stress range of $50-200 \mathrm{kPa}$. Each test is repeated three times to ensure the repeatability of the test results.

\subsubsection{Test Results}

Fig. 2 shows the stress-displacement curves for the GMB-GTX, GMB-GMB and GTXGTX interfaces at $200 \mathrm{kPa}$ normal stress. It can be observed that the shear stress increases with an increase in horizontal displacement up to a peak value beyond which it decreases with further increase in horizontal displacement and finally, becomes constant for the GMB-GTX and GMB-GMB interfaces. However, for the GTX-GTX interface, the shear stress increases with an increase in horizontal displacement up to a peak value beyond which it becomes constant. Moreover, the horizontal displacement corresponding to the peak is minimum for the GMB-GTX interface followed by the GMB-GMB and the GTXGTX interfaces. The secant slope of the stress-displacement curves at $50 \%$ of the peak shear stress for the GMB-GTX, GMB-GMB and GTX-GTX interfaces are $69.23 \mathrm{MN} / \mathrm{m}^{3}$, 80.03 MN/m $\mathrm{m}^{3}$ and $57.62 \mathrm{MN} / \mathrm{m}^{3}$, respectively. The secant slope is highest for the GMBGMB interface, whereas the slope of GMB-GTX interface is intermediate of the GMBGMB and GTX-GTX interfaces.

Fig. 3 shows the peak $(\mathrm{P})$ and residual (R) strength envelopes for the three interfaces. It can be observed that the shear strength increases linearly with an increase in normal stress for all the interfaces tested. The peak interface friction angles for the GMBGTX, GMB-GMB and GTX-GTX interfaces are $14.6^{\circ}, 19.8^{\circ}$ and $20.3^{\circ}$, respectively. Furthermore, the residual interface friction angles for the GMB-GTX, GMB-GMB and GTX-GTX interfaces are $13^{\circ}, 17.2^{\circ}$ and $20.3^{\circ}$, respectively. The friction angle of the GMB-GMB interface is higher than the GMB-GTX interface due to a large real contact area between the upper and lower geomembrane. As shown in Fig. 4, the geomembrane surface usually possesses minute irregularities/asperities. Therefore, the real contact area 
at the interface is usually smaller than the gross/apparent contact area, which is calculated using actual dimensions of the geosynthetic specimens (Stachowiak and Batchelor, 2013). The peak interface shear strength depends on the magnitude of the real contact area (Dove and Frost, 1999). An increase in the real contact area increases the peak interface shear strength. In the case of GMB-GTX interface, the real contact area may be much smaller due to the inherent fabric structure of the non-woven geotextile, which comprises randomly distributed fibres. Thus, the friction angle for the GMB-GTX interface is small. Whereas, for the GMB-GMB interface, the real contact area may be large (refer to Fig. 4). Therefore, the interface friction angle for the GMB-GMB interface is high. Nevertheless, further investigation is required to understand this behaviour.

\subsection{Dynamic Interface Shear Test}

\subsubsection{Test Apparatus and Procedure}

Fixed block type shake table tests have been conducted to study the shear behaviour of the GMB-GTX, GMB-GMB and GTX-GTX interfaces under dynamic loading conditions. Fig. 5 shows the schematic diagram of the fixed block type testing assembly for the dynamic interface shear tests. The test setup comprises three units: shearing unit, normal load unit and reaction unit. The shearing unit consists of a uniaxial shake table and a $10 \mathrm{~mm}$ thick steel plate (bottom steel plate). The shake table is a $2 \mathrm{~m} \times 2 \mathrm{~m}$, servocontrolled shake table with a horizontal and vertical load-carrying capacity of $50 \mathrm{kN}$ and $30 \mathrm{kN}$ respectively. The bottom steel plate is mounted over the shake table using $16 \mathrm{~mm}$ diameter bolts. One layer of the geosynthetic is fixed [glued (for geomembrane) and clamped (for geotextile)] to the bottom plate. The movement of the shake table generates the desired horizontal displacement at the geosynthetic-geosynthetic interface. The normal load unit consists of a $30 \mathrm{~mm}$ thick steel plate (upper steel plate), threaded steel 
rod and dead weights. To control the normal stress at the interface, a $115 \mathrm{~mm} \times 115 \mathrm{~mm}$ $\times 30 \mathrm{~mm}$ steel block is attached to the bottom of the upper steel plate. The size of the steel block was fixed to achieve the normal stress in the range of 51-148 $\mathrm{kPa}$. The second geosynthetic is attached [glued (for geomembrane) and clamped (for geotextile)] to the bottom of the steel block. The reaction unit consists of a connecting rod and a reaction frame. The reaction unit restricts the movement of the normal load unit (the portion above the geosynthetic-geosynthetic interface) and a dynamic load cell measures the total force required to prevent the movement of the normal load unit. A linear variable displacement transducer (LVDT) measured the table displacement.

Tests have been conducted on three interfaces: GMB-GTX, GMB-GMB and GTX-GTX. The size of the geomembrane specimens is fixed at $100 \mathrm{~mm} \times 100 \mathrm{~mm}$ and $400 \mathrm{~mm} \times 300 \mathrm{~mm}$ for the upper and lower portion, respectively. Moreover, the size of geotextile specimens is fixed at $200 \mathrm{~mm} \times 200 \mathrm{~mm}$ and $500 \mathrm{~mm} \times 500 \mathrm{~mm}$ for the upper and lower portion, respectively. The use of large-sized geosynthetic specimens for the lower portion ensures a uniform contact area (between the two geosynthetics) during the shearing. Furthermore, the size of the geotextile specimens is larger than the geomembrane specimens to fulfil the clamping requirements.

After the attachment of geosynthetics, a normal load is applied using a set of dead weights. Subsequently, the interface is subjected to a sinusoidal loading with a displacement amplitude and frequency of $15.91 \mathrm{~mm}$ and $1 \mathrm{~Hz}$, respectively, over a normal stress range of $51-148 \mathrm{kPa}$. The sinusoidal loading is useful to study the forcedisplacement behaviour of the dynamic systems and interfaces (De and Zimmie 1998; Yegian and Kadakal 1998; Park et al. 2004; Kotake and Kamon 2016). The companion paper by Punetha et al. (2019) provides a detailed description of the test setup and the 
procedure used to study the geosynthetic-geosynthetic interface shear behaviour under dynamic loading conditions.

\subsubsection{Dynamic Interface Test Results}

This section presents the results of the fixed block type shake table tests on geosyntheticgeosynthetic interfaces (GMB-GTX, GMB-GMB and GTX-GTX). Figs. 6(a) and 6(b) show the shear force-time history and the shear force-horizontal displacement curve, respectively, for the GMB-GTX interface at $97 \mathrm{kPa}$ normal stress. As can be seen, the shear force increases with an increase in horizontal displacement up to a peak value and becomes constant thereafter. The value of shear force remains constant till the half cycle is completed. In the next half cycle, the shear force again increases with an increase in horizontal displacement, but in an opposite direction. The shear force again reaches a peak value and becomes constant thereafter. This process continues till the end of the cycle. Thus, two plateau regions form during each cycle with a sustained value of shear force. The ratio of the sustained value of shear force to the normal load at the interface gives the dynamic coefficient of friction for the interface (Nanda et al. 2010).

The GTX-GTX interface, on the other hand, showed a post-peak strain hardening behaviour. Therefore, for GTX-GTX interface, the ratio of the maximum value of shear force to the normal load is taken as the dynamic coefficient of friction. Table 3 gives the values of the dynamic coefficient of friction for the three interfaces tested. The dynamic coefficient of friction for the GMB-GTX interface increases marginally from 0.22 to 0.24 , with an increase in normal stress from 51 to $112 \mathrm{kPa}$. The increase in the dynamic coefficient of friction may be attributed to the plastic deformation of the geomembrane surface below the geotextile fibres at high normal stress. Since, a high magnitude of shear force is required to push the fibres through the asperities formed due to plastic deformation of the geomembrane surface, the coefficient of friction increases. 
For the GMB-GMB interface, the dynamic coefficient of friction decreases from 0.24 at $68 \mathrm{kPa}$ normal stress to 0.21 at $148 \mathrm{kPa}$ normal stress. The reduction may be ascribed to the fact that the real contact area between the lower and upper geomembrane may increase at a lower rate as compared to the applied normal stress (Dove and Frost, 1999). Consequently, the dynamic coefficient of friction decreases with an increase in the normal stress. Moreover, for the GTX-GTX interface, the dynamic coefficient of friction decreases from 0.29 to 0.21 , with an increase in normal stress from 51 to $112 \mathrm{kPa}$. This reduction may be due to an increase in the number of fibre to fibre contacts with a rise in normal stress. The increase in the number of contacts reduces the contact stress and consequently, the coefficient of friction decreases.

The secant stiffness of the GMB-GTX, GMB-GMB and GTX-GTX interface at $50 \%$ of the peak shear force also increases with an increase in normal stress. For GMBGTX and GTX-GTX interface, the secant stiffness increases from 790 to $1026 \mathrm{kN} / \mathrm{m}$ and 379 to $1169 \mathrm{kN} / \mathrm{m}$, respectively, with an increase in normal stress from 51 to $112 \mathrm{kPa}$. The secant stiffness of GMB-GMB interface is the highest among all the interfaces, and its magnitude varies from 2852 to $3700 \mathrm{kN} / \mathrm{m}$ with an increase in normal stress from 68 to $148 \mathrm{kPa}$.

\section{Constitutive Modelling}

\subsection{Static Case}

For modelling the static case, the stress-displacement response of the interface is divided into three zones, namely, pre-peak, peak and post-peak zone.

\subsubsection{Pre-peak Zone}

Figs. 7(a), 7(b) and 7(c) show the predicted vs. the experimental shear stress-displacement curves for GMB-GTX, GMB-GMB and GTX-GTX interfaces, respectively. It is clear 
from the experimental stress-displacement curves that all the three interfaces show a nonlinear pre-peak behaviour. The hyperbolic model given by Kondner (1963) has been used to model the non-linear pre-peak behaviour of the interfaces.

$$
\tau=\frac{\delta}{\frac{1}{K_{\mathrm{s}}}+\frac{\delta}{\tau_{\mathrm{ult}}}}
$$

where $\tau=$ shear stress $\delta=$ horizontal displacement; $K_{\mathrm{S}}=$ initial slope of shear stress vs. horizontal displacement curve; $\tau_{\mathrm{ult}}=$ ultimate shear stress. In Equation (1), $K_{\mathrm{s}}$ and $\tau_{\mathrm{ult}}$ are the two unknown parameters which are determined using the experimental data. In some interfaces, the initial slope of the stress-displacement curves depends on the normal stress. From Fig. 7(c), it can be observed that for the GTX-GTX interface, the initial slope increases with an increase in the normal stress. The expression given by Reddy et al. (1996) [Equation (2)] has been used to model this pressure-dependent behaviour.

$$
K_{\mathrm{s}}=K \gamma_{\mathrm{w}}\left(\frac{\sigma_{\mathrm{n}}}{P_{\mathrm{a}}}\right)^{N}
$$

To account for the non-linear behaviour in the model, instantaneous slope has been calculated using the expression given by Reddy et al. (1996):

$$
K_{\mathrm{t}}=K \gamma_{\mathrm{w}}\left(\frac{\sigma_{\mathrm{n}}}{P_{\mathrm{a}}}\right)^{N}\left[1-R_{\mathrm{f}}\left(\frac{\tau}{\tau_{\mathrm{p}}}\right)\right]^{2}
$$

where $K_{\mathrm{t}}=$ instantaneous slope of the stress-displacement curve; $K=$ modulus number; $\gamma_{\mathrm{w}}=$ unit weight of water; $\sigma_{\mathrm{n}}=$ normal stress; $P_{\mathrm{a}}=$ atmospheric pressure; $N=$ modulus exponent; $R_{\mathrm{f}}=$ failure ratio; $\tau_{\mathrm{p}}=$ peak shear strength. The parameter $N$ depicts the dependency of the initial slope on the normal stress. A small value of $N$ (equal to 0 ) shows pressure-independent behaviour, while a large value (about 1) represents the pressuredependent behaviour. The failure ratio is the ratio of the peak shear strength to the ultimate shear stress, and its value is always less than one. 


$$
R_{\mathrm{f}}=\frac{\tau_{\mathrm{p}}}{\tau_{\mathrm{ult}}}
$$

\subsubsection{Peak Zone}

To model the peak shear strength, the Mohr-Coulomb's criterion has been used.

$$
\tau_{\mathrm{p}}=c_{\mathrm{p}}+\sigma_{\mathrm{n}} \tan \varphi_{\mathrm{p}}
$$

where $c_{\mathrm{p}}=$ peak adhesion intercept $; \varphi_{\mathrm{p}}=$ peak interface friction angle.

\subsubsection{Post-peak Zone}

Some interfaces show post-peak strain hardening/ softening behaviour while for others, the shear stress becomes constant after the peak. In the present study, the GMB-GTX and GMB-GMB interfaces show a strain-softening behaviour, while for the GTX-GTX interface, the shear stress became constant after the peak. The strain-softening behaviour has been modelled using the method given by Anubhav and Basudhar (2010). Initially, the relationship between the reduction factor and the horizontal displacement is established. The reduction factor is the post-peak reduction in shear stress normalised by the shear stress reduction from peak to the residual value.

$$
R=\frac{\tau_{\mathrm{p}}-\tau}{\tau_{\mathrm{p}}-\tau_{\mathrm{r}}}
$$

where $\tau_{\mathrm{p}}=$ peak shear strength; $\tau_{\mathrm{r}}=$ residual shear strength. $\tau_{\mathrm{r}}$ can be evaluated using Equation (5) by replacing $c_{\mathrm{p}}$ and $\varphi_{\mathrm{p}}$ with $c_{\mathrm{r}}$ (residual adhesion intercept) and $\varphi_{\mathrm{r}}$ (residual interface friction angle), respectively. For the present case, the reduction factor varies with the horizontal displacement as:

$$
R=x+y e^{-z \delta^{-n}}
$$

where $R$ is the reduction factor; $\delta$ is the horizontal displacement; $x, y, z$ and $n$ are constants. For interfaces showing a constant value of shear stress after the peak, the previously described method is slightly modified. The modified method involves the use of the 
hyperbolic function to model the pre-peak behaviour (similar to the method described above). However, after the peak, the shear stress is assumed to be constant and equal to the peak value. In other words, the reduction factor is assumed to be equal to zero. Table 4 shows the values of the modelling parameters and the constants of the Equation (7) used in the present study. A code was developed in MATLAB to evaluate the magnitude of shear stress corresponding to a particular value of horizontal displacement using Equations (1-7).

\subsubsection{Results}

From Fig. 7, it can be observed that the back-fitted stress-displacement response of the three interfaces matches quite well with the experimental results, with an average variation of about 15\%, 24\% and 11\% for GMB-GTX, GMB-GMB and GTX-GTX interfaces, respectively. The model is able to reproduce the shear behaviour of the geosynthetic-geosynthetic interfaces involving smooth geomembrane and nonwoven geotextile over the range of normal stresses used in experiments. Moreover, the model can also be used to interpolate the response at the normal stresses which are difficult to generate in the laboratory. Similarly, by varying the modelling parameters, the response of the interface can also be predicted at different testing conditions.

\subsection{Dynamic Case}

For modelling the interface behaviour under dynamic loading conditions, the method used in the static case has been modified.

\subsubsection{Pre-peak Zone}

A close observation of the experimental shear force vs. horizontal displacement curve for GMB-GTX interface in Fig. 8(a) reveals that the behaviour is non-linear in the initial portion of the first half cycle. Therefore, to simulate this portion, the hyperbolic model 
given by Kondner (1963) has been used. As shown in Equation (8), the only difference in the two cases (static and dynamic) is that the shear force has replaced the shear stress in the dynamic case.

$$
S=\frac{\delta}{\frac{1}{K_{\mathrm{s}}{ }^{\prime}}+\frac{\delta}{S_{\mathrm{ult}}}}
$$

where $S=$ shear force; $\delta=$ horizontal displacement; $K_{\mathrm{S}}^{\prime}=$ initial slope of shear force vs. horizontal displacement curve; $S_{\text {ult }}=$ ultimate shear force. The values of $K_{\mathrm{s}}^{\prime}$ and $S_{\text {ult }}$ are calculated using the experimental data (by back analysis). For determination of the instantaneous slope of the shear force-displacement curve, the Equations (2) and (3) described above have been modified as:

$$
\begin{gathered}
K_{\mathrm{s}}{ }^{\prime}=K a\left(\frac{F}{b}\right)^{N} \\
K_{\mathrm{t}}{ }^{\prime}=K a\left(\frac{F}{b}\right)^{N}\left[1-R_{\mathrm{f}}\left(\frac{S}{S_{\mathrm{p}}}\right)\right]^{2}
\end{gathered}
$$

where $K_{\mathrm{t}}^{\prime}=$ instantaneous slope of the shear force-displacement curve; $K=$ modulus number; $F=$ normal force; $N=$ modulus exponent; $R_{\mathrm{f}}=$ failure ratio; $S_{\mathrm{p}}=$ peak shear force; $a$ and $b$ are constants. The parameter ' $b$ ' is used to make the term $F / b$ dimensionless and ' $a$ ' is used to make the equation dimensionally stable. The values of the parameters ' $a$ ' and ' $b$ ' are taken as $1 \mathrm{kN} / \mathrm{m}$ and $1 \mathrm{kN}$ respectively in the present study. The parameters $K$ and $N$ are determined using Equation (10) and the experimental data.

\subsubsection{Peak Zone}

The peak value of the shear force $\left(S_{p}\right)$ is modelled using the Equation (11):

$$
S_{\mathrm{p}}=F \mu_{\mathrm{d}}
$$

where $\mu_{\mathrm{d}}$ is the dynamic coefficient of friction. 


\subsubsection{Post-peak Zone}

After attaining a peak value, the shear force remains constant throughout the rest of the half cycle irrespective of the displacement. With the change in direction of sliding, the shear force increases in the opposite direction up to a peak value. The change of direction is predicted by calculating the value of sliding velocity (by differentiating the horizontal displacement). The negative value of velocity indicates a change in sliding direction. A similar procedure is used to predict the value of shear force for the rest of the half cycle. The experimental results show isometric hardening behaviour of the interfaces and therefore similar behaviour is assumed in modelling.

Fig. 8(a) shows the predicted vs. experimental force-displacement curves for the GMB-GTX interface at $51 \mathrm{kPa}$ normal stress. It can be observed that the back-fitted forcedisplacement curves are in good agreement with the experimental results. Fig. 8(b) shows the predicted vs. experimental shear force-time history for GMB-GTX interface at $51 \mathrm{kPa}$ normal stress. It can be observed that the back-fitted force-time history matches well with the experimental results. Similarly, for GMB-GMB interface, the back-fitted results match well with the experimental results as shown in Figs. 9(a-b).

Figs. 10(a) and 10(b) show the force-displacement curve and the shear force-time history for the GTX-GTX interface at $66 \mathrm{kPa}$ normal stress. It is evident that the GTXGTX interface shows a post-peak strain hardening behaviour. The shear force increases continuously with an increase in horizontal displacement throughout the rest of the half cycle at a low rate, after attaining an initial peak value. A similar behaviour i.e. a continuous increment in shear force at a low rate is observed in the opposite direction with the change in the direction of sliding after the half cycle. The strain hardening behaviour could be due to the stretching of fibres of the lower geotextile during shear, in the contact region. As the shearing progresses, the fibres of the bottom geotextile in the 
contact zone get stretched and produce wrinkles in the portion adjacent to the edge of the contact zone (in the direction of shear). The wrinkles present near the edge of the contact zone oppose the motion as the shearing progresses and therefore, results in post-peak strain hardening. For modelling this post-peak strain hardening behaviour, the residual factor method (similar to the one used in static case) has been used. This method involves the establishment of a relationship between the reduction factor and the horizontal displacement. This relationship is used to calculate the shear force at any horizontal displacement using Equation (12).

$$
R=\frac{S_{\mathrm{p}}-S}{S_{\mathrm{p}}-S_{\mathrm{r}}}
$$

where $S_{\mathrm{p}}=$ peak shear force; $S_{\mathrm{r}}=$ residual shear force. Fig. 10(c) shows the relationship between the reduction factor and the horizontal displacement. This relationship has been evaluated using a non-linear regression analysis in MATLAB and the expression is given in Equation (13).

$$
R=x e^{y \delta}+z e^{n \delta}
$$

The value of the constants $(x, y, n$ and $z)$ of the best fit curve and the value of other modelling parameters is given in Table 5. It can be seen from Figs. 10(a-b) that the backfitted results are in good agreement with the experimental ones. Thus, the back-fitted stress displacement curves for the three interfaces match quite well with the corresponding experimental curves, with an average variation of $25 \%$. It must be noted that the scope of the present study is limited to the development of the constitutive model for the geosynthetic-geosynthetic interfaces under static and dynamic loading conditions. The future scope of the work includes the implementation of the proposed model in the commercially available finite element/ finite difference based software and subsequent prediction of the response of geosynthetic-geosynthetic interfaces. 


\section{Conclusions}

The present study deals with the constitutive modelling of the GMB-GTX, GMB-GMB and GTX-GTX interfaces under static and dynamic loading conditions. The results of the laboratory direct shear tests and fixed block type shake table tests on the three interfaces revealed that the stress/force-displacement behaviour of the interfaces could be divided into three zones: non-linear pre-peak zone, peak and post-peak zone (involving strain softening/hardening or perfectly plastic behaviour). The models originally developed for predicting the soil-structure interface shear behaviour under static loading conditions were extended to reproduce the force/stress-displacement response of the three interfaces under static and dynamic loading conditions. The results of the experimental investigation were used to obtain the modelling parameters by back analysing the experimental data.

Using the parameters (derived from the experimental data), the back-fitted stress/force-displacement response of the interfaces showed excellent agreement with the experimental data over the range of normal stresses used in the present study. The interface shear behaviour of all the interfaces under static and dynamic loading conditions was simulated using the same model with slight modifications.

The present study provides a constitutive model for predicting the response of geosynthetic-geosynthetic interfaces involving smooth geomembrane and nonwoven geotextile under static and dynamic loading conditions. The constitutive modelling is particularly useful for the interpolation of interface behaviour for the testing conditions which are difficult to generate at the laboratory level. This study is essential to predict the response of the structures involving geosynthetic-geosynthetic interface and assess their long-term performance. 


\section{Acknowledgements}

The authors would like to acknowledge the Director, CSIR-CBRI Roorkee for providing the infrastructural facilities for conducting experimental work, continuous guidance and support. The authors would also like to thank the anonymous reviewers for their valuable time and suggestions.

\section{References}

Anubhav, Basudhar PK (2010) Modeling of soil-woven geotextile interface behavior from direct shear test results. Geotextiles and Geomembranes, 28(4): 403-408. http://doi.org/10.1016/j.geotexmem.2009.12.005

Anubhav, Wu H (2015) Modelling of non-linear shear displacement behaviour of soilgeotextile interface. Int $\mathbf{J}$ of Geosynth and Ground Eng 1-19. http://doi.org/10.1007/s40891-015-0021-7

Arab MG, Kavazanjian E, Fox PJ, Matasovic N (2012) In plane-behavior of geosynthetic barrier layers subject to cyclic loading. In: Proceedings of $2^{\text {nd }}$ international conference on performance based design in earthquake geotechnical engineering, Taormina, Sicily, Italy, May 2002, Paper (No. 3.11).

ASTM D 4354 (2012) Standard practice for sampling of geosynthetics and rolled erosion control products (RECPs) for testing. American Society for Testing and Materials, West Conshohocken, Pennsylvania, USA.

ASTM D 5321 (2014) Standard test method for determining the coefficient of soil and geosynthetic or geosynthetic and geosynthetic friction by the direct shear method. American Society for Testing and Materials, West Conshohocken, Pennsylvania, USA.

Bacas BM, Cañizal J, Konietzky H (2015) Shear strength behavior of geotextile/geomembrane interfaces. Journal of Rock Mechanics and Geotechnical Engineering, 7(6): 638-645. http://doi.org/10.1016/j.jrmge.2015.08.001

Bacas BM, Konietzky H, Berini JC, Sagaseta C (2011) A new constitutive model for textured geomembrane/geotextile interfaces. Geotextiles and Geomembranes, 29(2): 137-148. http://doi.org/10.1016/j.geotexmem.2010.10.014

Bergado DT, Ramana GV, Sia HI (2006) Evaluation of interface shear strength of composite liner system and stability analysis for a landfill lining system in 
Thailand. Geotextiles and Geomembranes, 24(6): 371-393. http://doi.org/10.1016/j.geotexmem.2006.04.001

De A, Zimmie TF (1998) Estimation of dynamic interfacial properties of geosynthetics. Geosynthetics International, 5(1-2): 17-39. http://dx.doi.org/10.1680/gein.5.0112 Dove JE, Frost JD (1999) Peak friction behavior of smooth geomembrane-particle interfaces. Journal of Geotechnical and Geoenvironmental Engineering, 125(7): 544-555. https://doi.org/10.1061/(ASCE)1090-0241(1999)125:7(544)

Esterhuizen JJ, Filz GM, Duncan JM (2001) Constitutive behavior of geosynthetic interfaces. Journal of Geotechnical and Geoenvironmental Engineering, 127(10): 834-840. http://dx.doi.org/10.1061/(ASCE)1090-0241(2001)127:10(834)

Georgarakos P, Yegian MK, Gazetas G (2005) In-ground isolation using geosynthetic liners. In: Proceedings of 9th World Seminar on Seismic Isolation, Energy Dissipation and Active Vibration Control of Structures, Kobe, Japan, June 2005.

Gilbert RB, Byrne RJ (1996) Strain-softening behavior of waste containment system interfaces. Geosynthetics International, 3(2): 181-203. http://dx.doi.org/10.1680/gein.3.0059

Guo W, Chu J (2016). Model tests and parametric studies of two-layer geomembrane $\begin{array}{llll}\text { tubes. } & \text { Geosynthetics }\end{array}$ http://dx.doi.org/10.1680/jgein.15.00043

Hushmand B, Martin GR (1991) Layered soil-synthetic liner base isolation system. NSF Small Business Innovative Research Program, Final Report.

Kavazanjian E, Hushmand B, Martin GR (1991) Frictional base isolation using a layered soil-synthetic liner system. In: Proceedings on 3rd U.S. Conference on Lifeline Earthquake Engineering, Los Angeles, USA, August 1991, pp. 1140-1151.

Kondner RL (1963) Hyperbolic stress-strain response: cohesive soils. Journal of Soil Mechanics and Foundations Division ASCE, 89(1): 289-324.

Kotake N, Kamon M (2016). Seismic stability of geosynthetic barrier on landfill slope. Japanese Geotechnical Society Special Publication, 2(69): 2352-2356. http://doi.org/10.3208/jgssp.IGS-42

Krahn T, Blatz J, Alfaro M, Bathurst R J (2007) Large-scale interface shear testing of sandbag dyke materials. Geosynthetics International, 14(2): 119-126. http://dx.doi.org/10.1680/gein.2007.14.2.119 
Liu H, Ling HI (2006) Modeling cyclic behavior of geosynthetics using mathematical functions combined with Masing rule and bounding surface plasticity. $\begin{array}{llll}\text { Geosynthetics } & \text { International, }\end{array}$ http://dx.doi.org/10.1680/gein.2006.13.6.234

Lohani TN, Matsushima K, Aqil U, Mohri Y, Tatsuoka F (2006) Evaluating the strength and deformation characteristics of a soil bag pile from full-scale laboratory tests. $\begin{array}{lll}\text { Geosynthetics } & \text { International, }\end{array}$ http://dx.doi.org/10.1680/gein.2006.13.6.246

Lopes ML, Silvano R (2010) Soil/Geotextile Interface Behaviour in Direct Shear and Pullout Movements. Geotech Geol Eng 28: 791. https://doi.org/10.1007/s10706$\underline{010-9339-\mathrm{Z}}$

Mariappan S, Kamon M, Ali FH et al. (2011) Performances of Landfill Liners under Dry and Wet Conditions. Geotech Geol Eng 29: 881. https://doi.org/10.1007/s10706$\underline{011-9426-9}$

MATLAB 7.13 [Computer software]. MathWorks, Natick, MA.

Moreira A, Vieira CS, Neves LD, Lopes ML (2013) Influence of the displacement rate on direct shear behavior of geotextile interfaces. In: Proceedings of Geosintec Iberia 1, University of Porto, Portugal, pp. 171-178.

Moreira A, Vieira CS, Neves LD, Lopes ML (2016) Assessment of friction properties at geotextile encapsulated-sand systems interfaces used for coastal protection. Geotextiles and Geomembranes, 44(3): 278-286. http://doi.org/10.1016/j.geotexmem.2015.12.002

Nanda RP, Agarwal P, Shrikhande M (2010) Friction base isolation by geotextiles for brick masonry buildings. Geosynthetics International, 17(1): 48-55. http://dx.doi.org/10.1680/gein.2010.17.1.48

Park IJ, Seo MW, Park JB, Kwon SY, Lee JS (2004) Estimation of the dynamic properties for geosynthetic interfaces. In: Proceedings of 13th World Conference on Earthquake Engineering, Vancouver, BC, Canada, August 2004, Paper (No. 3210).

Punetha P, Samanta M (2017) Study on deformed microstructure of geosynthetics in interface direct shear test. In: Proceedings of the 6th Indian Young Geotechnical Engineers Conference 2017, NIT Trichy, India, March 2017, pp. 265-270. 
Punetha P, Mohanty P, Samanta M (2016) Study on interface shear strength of soilgeosynthetics in large direct shear box. In: Proceedings of the 6th Asian regional conference on Geosynthetics- Geosynthetics for Infrastructure Development, CBIP, New Delhi, India, November 2016, pp. 345-356.

Punetha P, Mohanty P, Samanta M (2017) Microstructural investigation on mechanical behavior of soil-geosynthetic interface in direct shear test. Geotextiles and Geomembranes, 45(3): 197-210. http://doi.org/10.1016/j.geotexmem.2017.02.001

Punetha P, Samanta M, Mohanty P (2019) Evaluation of dynamic response of geosynthetic interfaces. International Journal of Physical Modelling in Geotechnics 19(3): 141-153. https://doi.org/10.1680/jphmg.17.00045

Reddy KR, Kosgi S, Motan ES (1996) Interface shear behavior of landfill composite liner systems: a finite element analysis. Geosynthetics International, 3(2): 247-275. http://doi.org/10.1680/gein.3.0062

Seo MW, Park JB, Park IJ, Chung MK (2003) Modeling of interface shear behavior between geosynthetics. KSCE Journal of Civil Engineering, 7(1): 9-16. https://doi.org/10.1007/bf02841987

Stachowiak G, Batchelor AW (2013) Engineering Tribology. Elsevier Science and Technology, Oxford.

Stark TD, Niazi FS, Keuscher TC (2015) Strength envelopes from single and multi geosynthetic interface tests. Geotechnical and Geological Engineering, 33(5): 1351-1367. https://doi.org/10.1007/s10706-015-9906-4

Yegian MK, Catan M (2004) Soil isolation for seismic protection using a smooth synthetic liner. Journal of Geotechnical and Geoenvironmental engineering, 130(11): $\quad$ 1131-1139. $\quad$ http://dx.doi.org/10.1061/(ASCE)10900241(2004)130:11(1131)

Yegian MK, Kadakal U (1998) Geosynthetic interface behavior under dynamic loading. Geosynthetics International, 5(1-2): 1-16. http://dx.doi.org/10.1680/gein.5.0111

Yegian MK, Kadakal U (2004) Foundation isolation for seismic protection using a smooth synthetic liner. Journal of Geotechnical and Geoenvironmental Engineering, 130(11): 1121-1130. $\quad$ http://dx.doi.org/10.1061/(ASCE)1090$\underline{\text { 0241(2004)130:11(1121) }}$ 
Yegian MK, Lahlaf AM (1992) Dynamic interface shear strength properties of geomembranes and geotextiles. Journal of Geotechnical Engineering, 118(5): 760-779. http://dx.doi.org/10.1061/(ASCE)0733-9410(1992)118:5(760) 


\section{Table Captions}

Table 1 Properties of nonwoven needle-punched geotextile

Table 2 Properties of smooth HDPE geomembrane

Table 3 Results of the dynamic interface shear tests

Table 4 Values of the parameters used for constitutive modelling of static interface behaviour

Table 5 Values of the parameters used for constitutive modelling of dynamic interface behaviour 


\section{Figure Captions}

Fig. 1 Schematic diagram of modified large-size direct shear box test assembly

Fig. 2 Shear stress vs. horizontal displacement curves for GMB-GTX, GMB-GMB and GTX-GTX interfaces at $200 \mathrm{kPa}$ normal stress

Fig. 3 Peak and residual strength envelopes for GMB-GTX, GMB-GMB and GTX-GTX interfaces for static loading condition

Fig. 4 Real contact area for GMB-GTX and GMB-GMB interfaces

Fig. 5 Schematic illustration of the fixed block type testing assembly for the dynamic interface shear tests

Fig. 6 (a) Shear force-time history for the GMB-GTX interface at $97 \mathrm{kPa}$ normal stress; (b) force-displacement curve for the GMB-GTX interface at $97 \mathrm{kPa}$ normal stress

Fig. 7 Experimental vs. predicted stress-displacement curves for (a) GMB-GTX interface; (b) GMB-GMB interface; (c) GTX-GTX interface

Fig. 8 Experimental vs. predicted behaviour of GMB-GTX interface at $51 \mathrm{kPa}$ normal stress (a) force-displacement curve; (b) shear force-time history

Fig. 9 Experimental vs. predicted behaviour of GMB-GMB interface at $88 \mathrm{kPa}$ normal stress (a) force-displacement curve; (b) shear force-time history

Fig. 10 Experimental vs. predicted behaviour of GTX-GTX interface at $66 \mathrm{kPa}$ normal stress: (a) force-displacement curve; (b) shear force-time history; (c) variation of reduction factor with horizontal displacement 


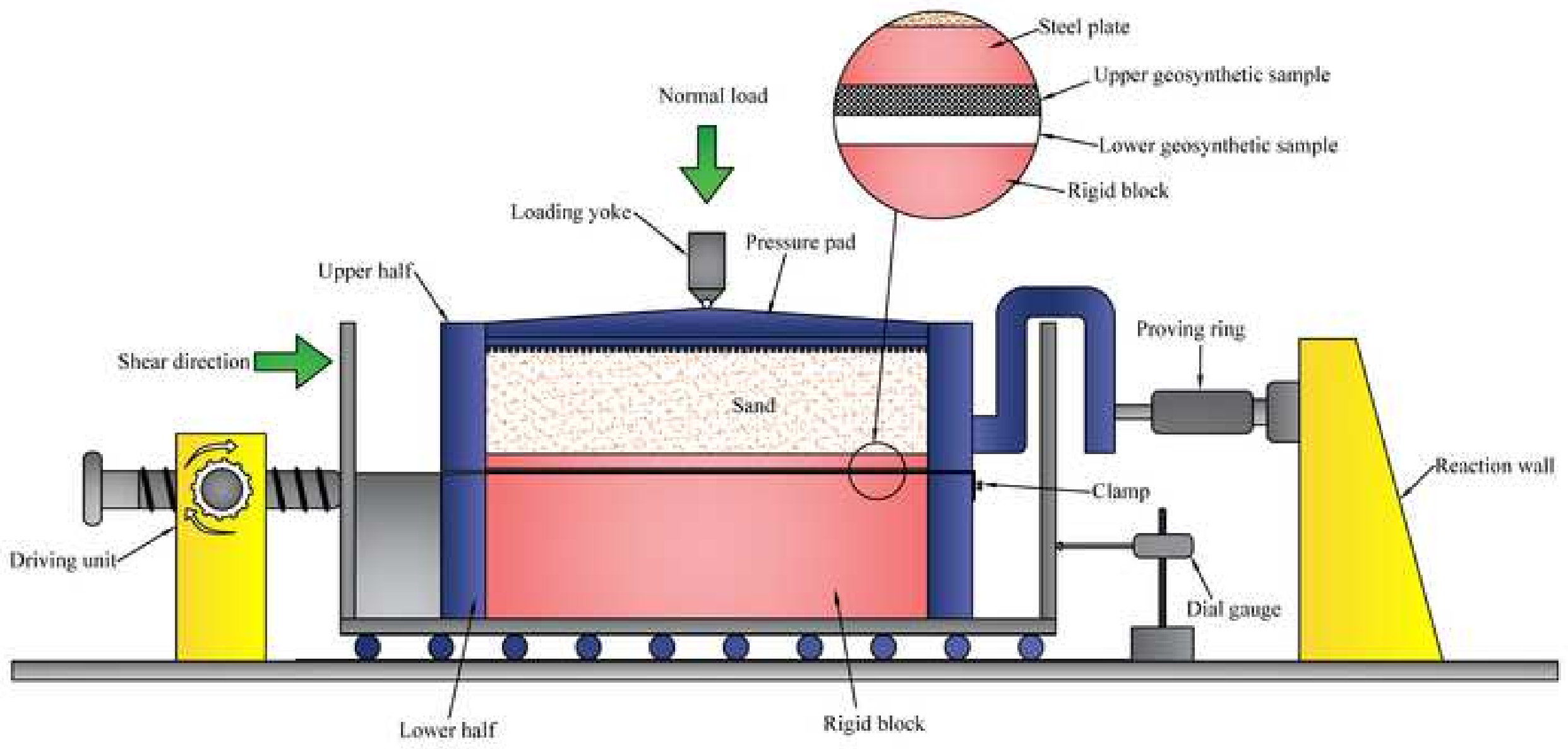




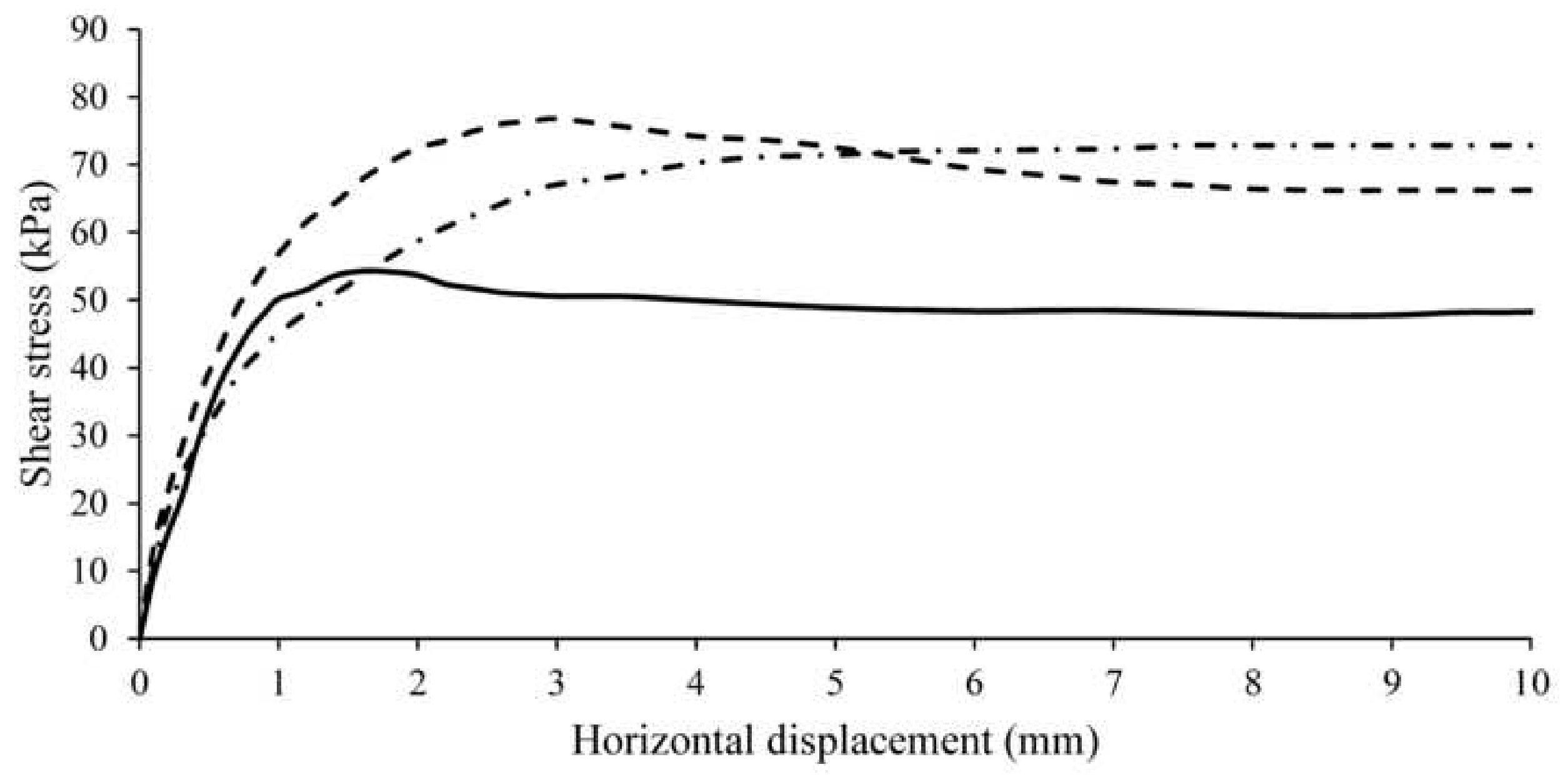

—GMB-GTX $\quad---$ GMB-GMB $\quad-\cdot$ GTX-GTX 


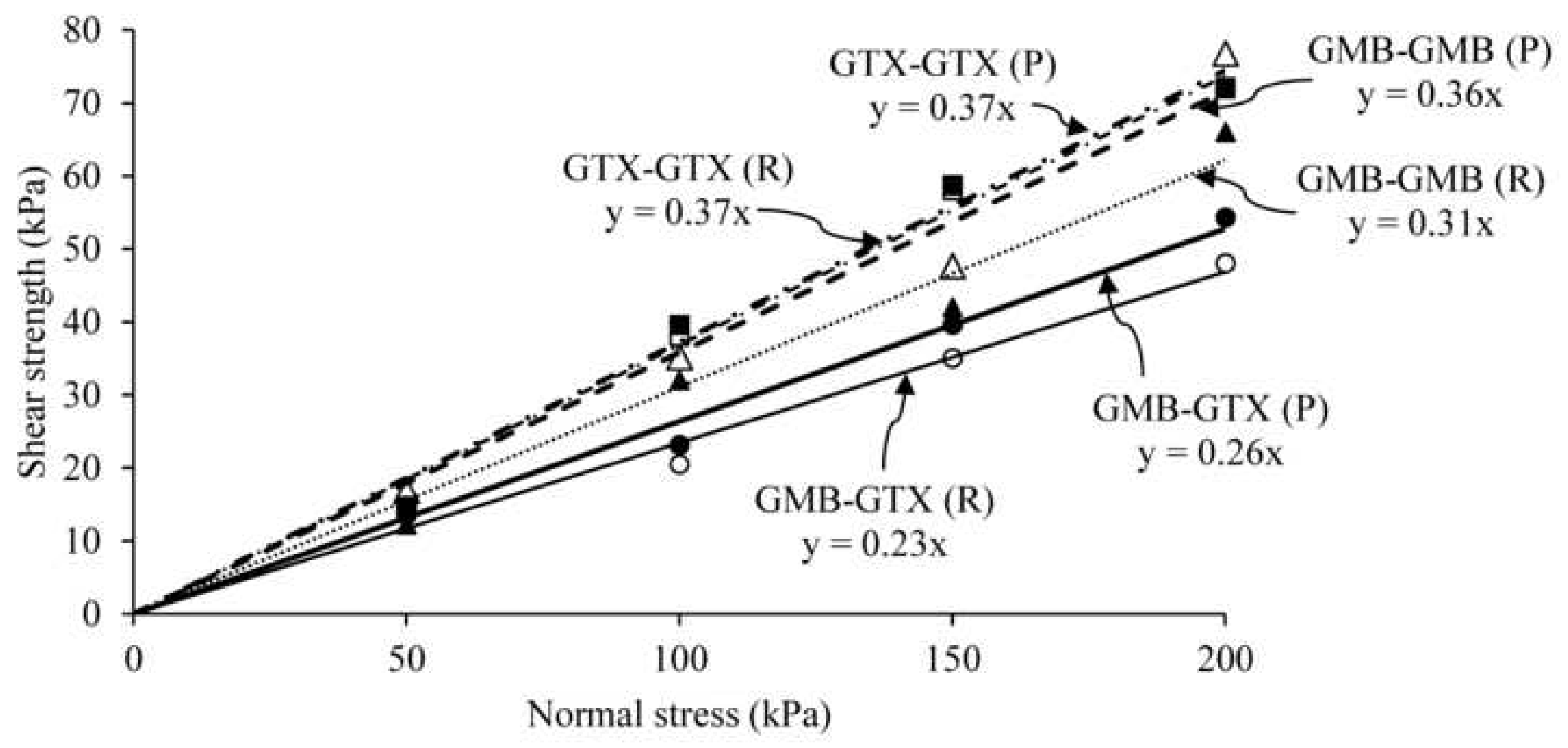

- GMB-GTX (P)

O GMB-GTX (R)

$\triangle$ GMB-GMB (P)

A GMB-GMB (R)

-GTX-GTX (P)

口GTX-GTX (R) 


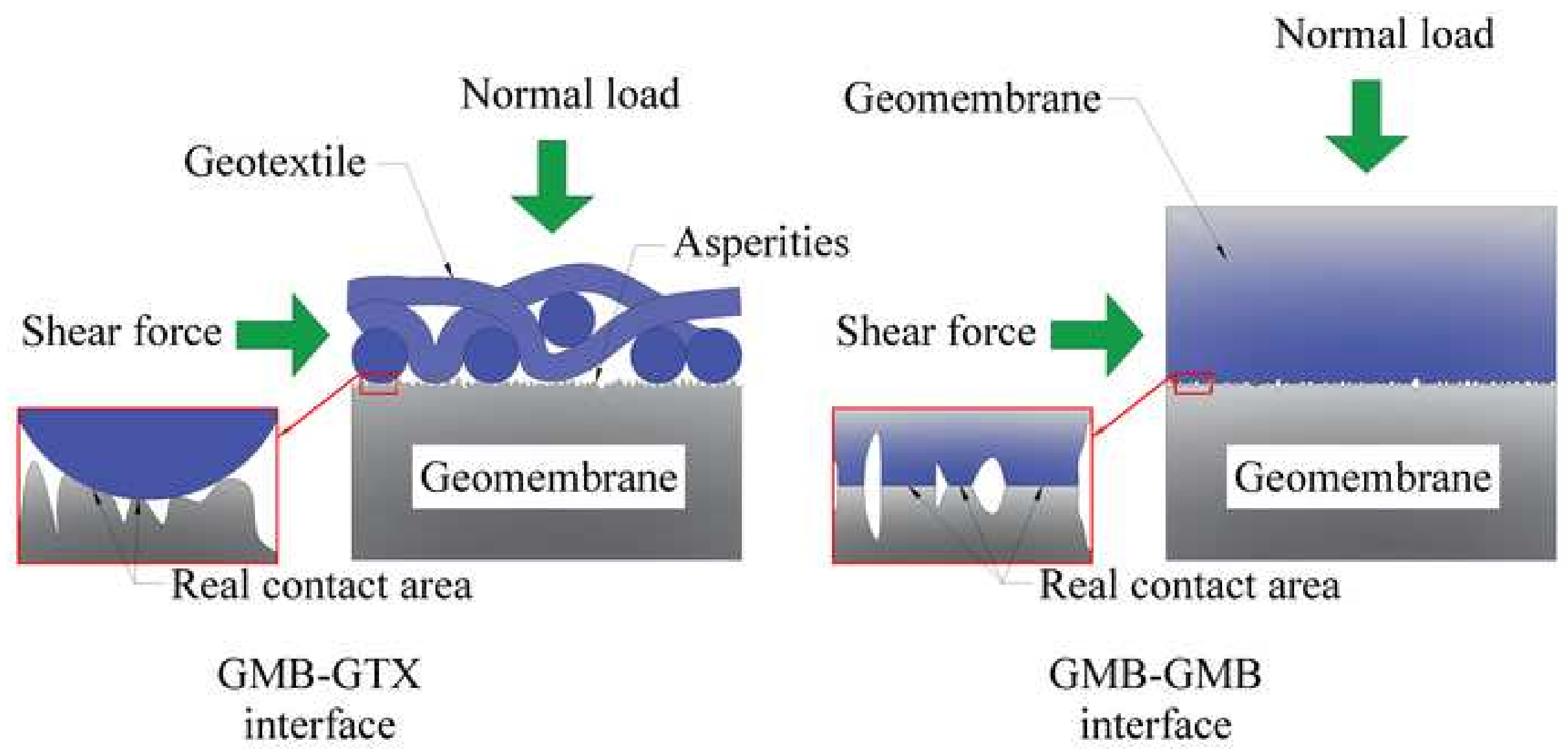




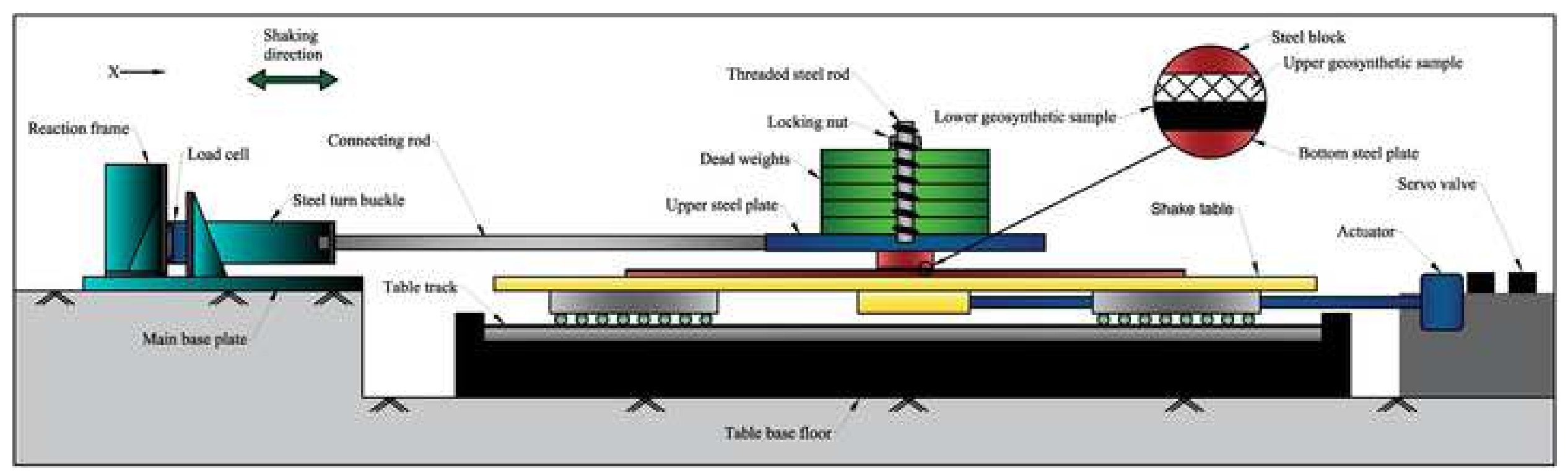




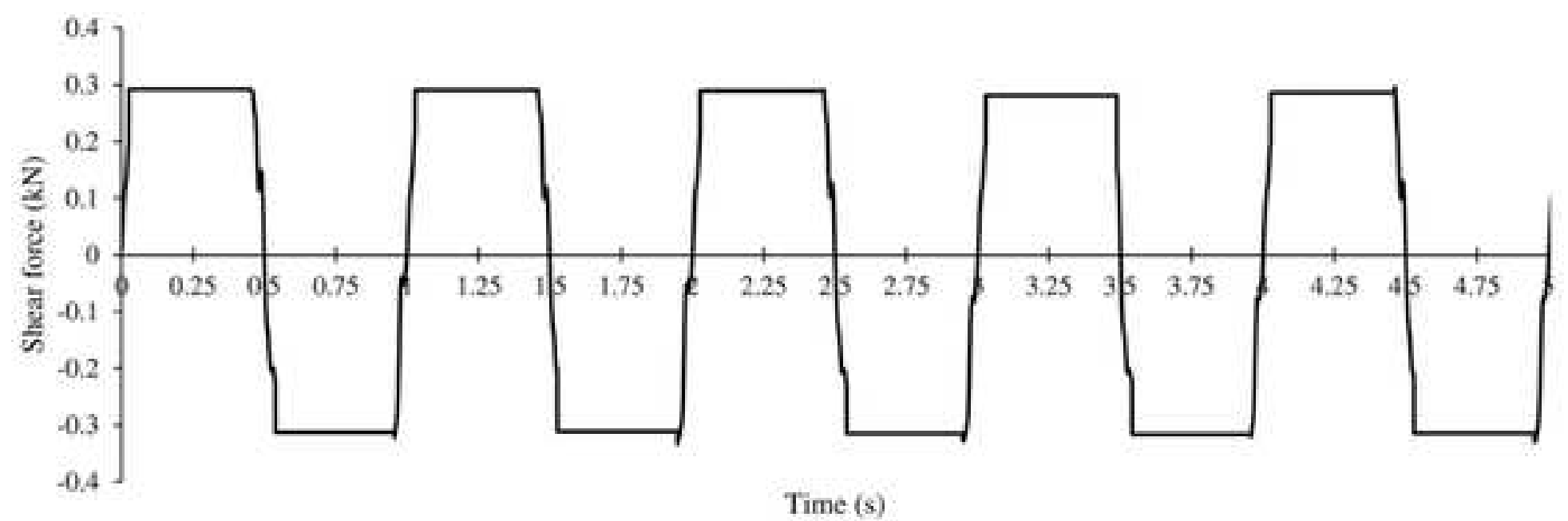

(a)

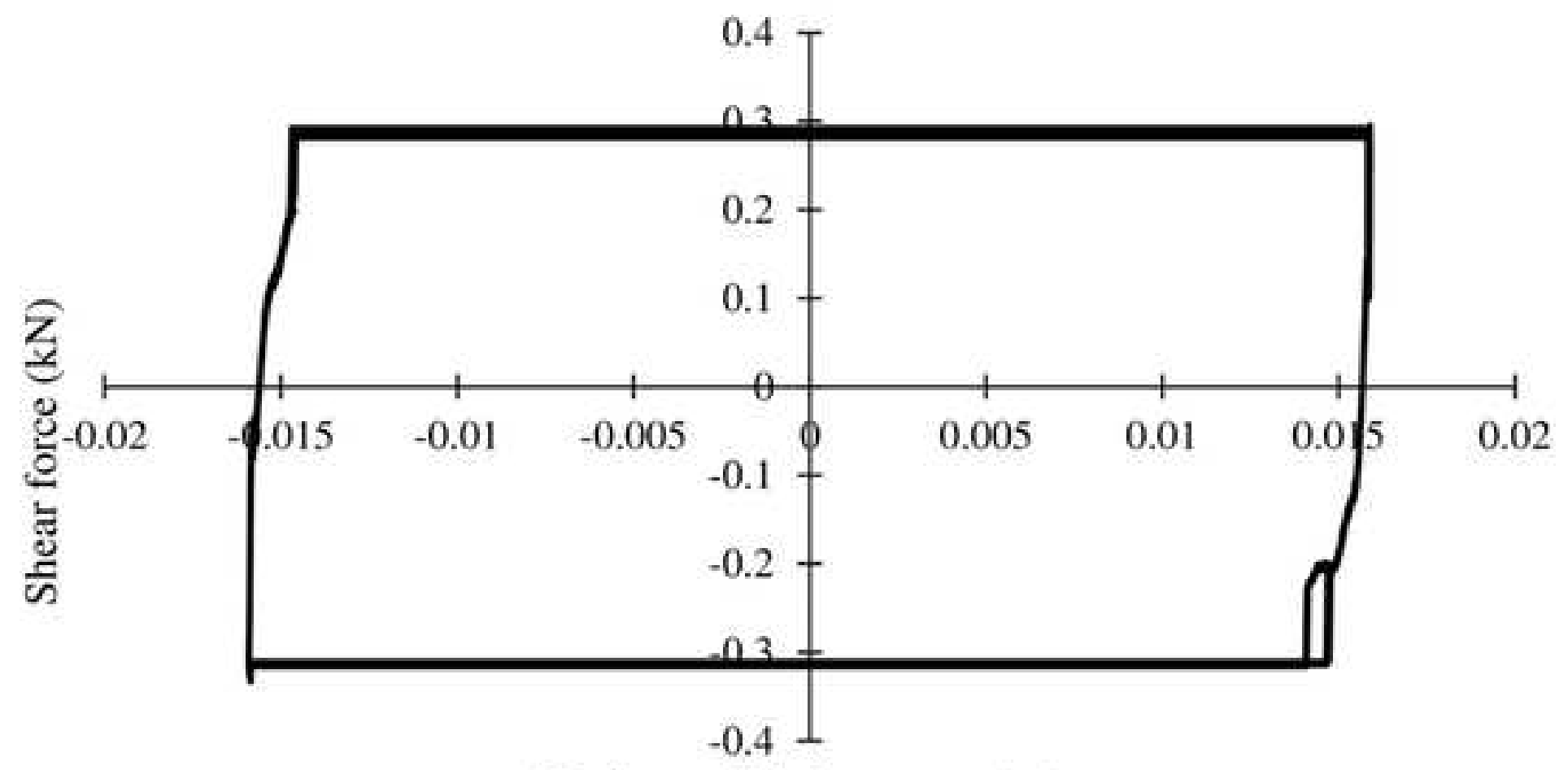

Horizontal displacement (m)

(b) 


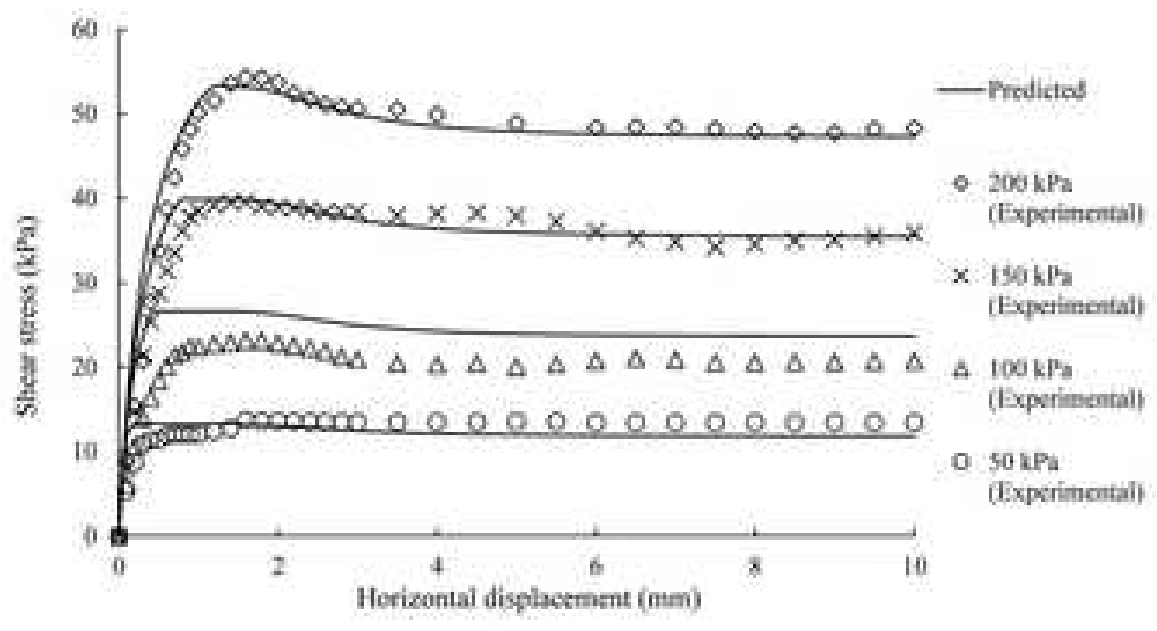

(a)

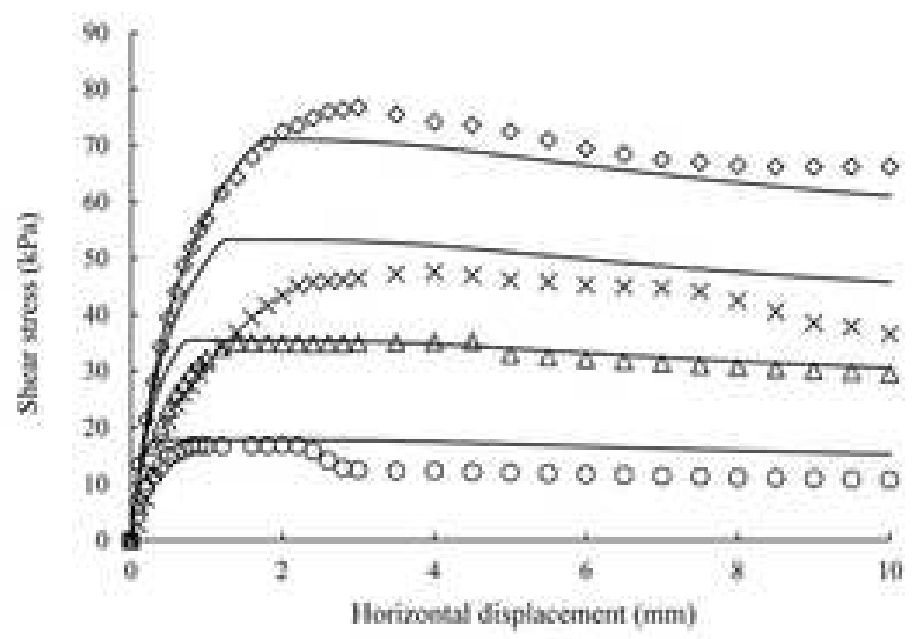

(b)

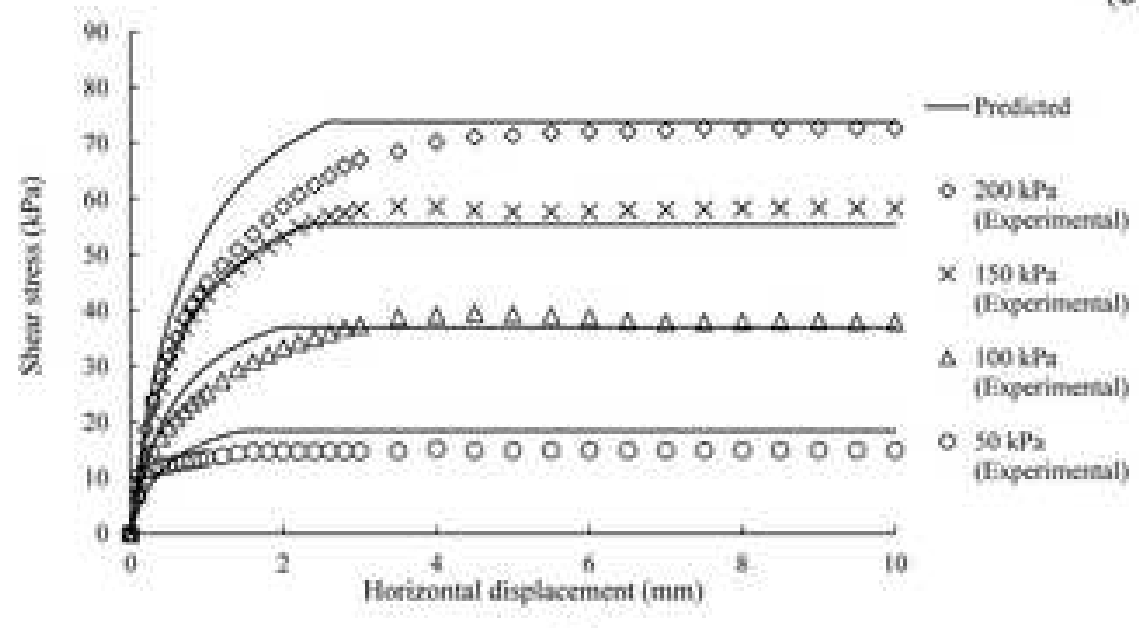

(c) 


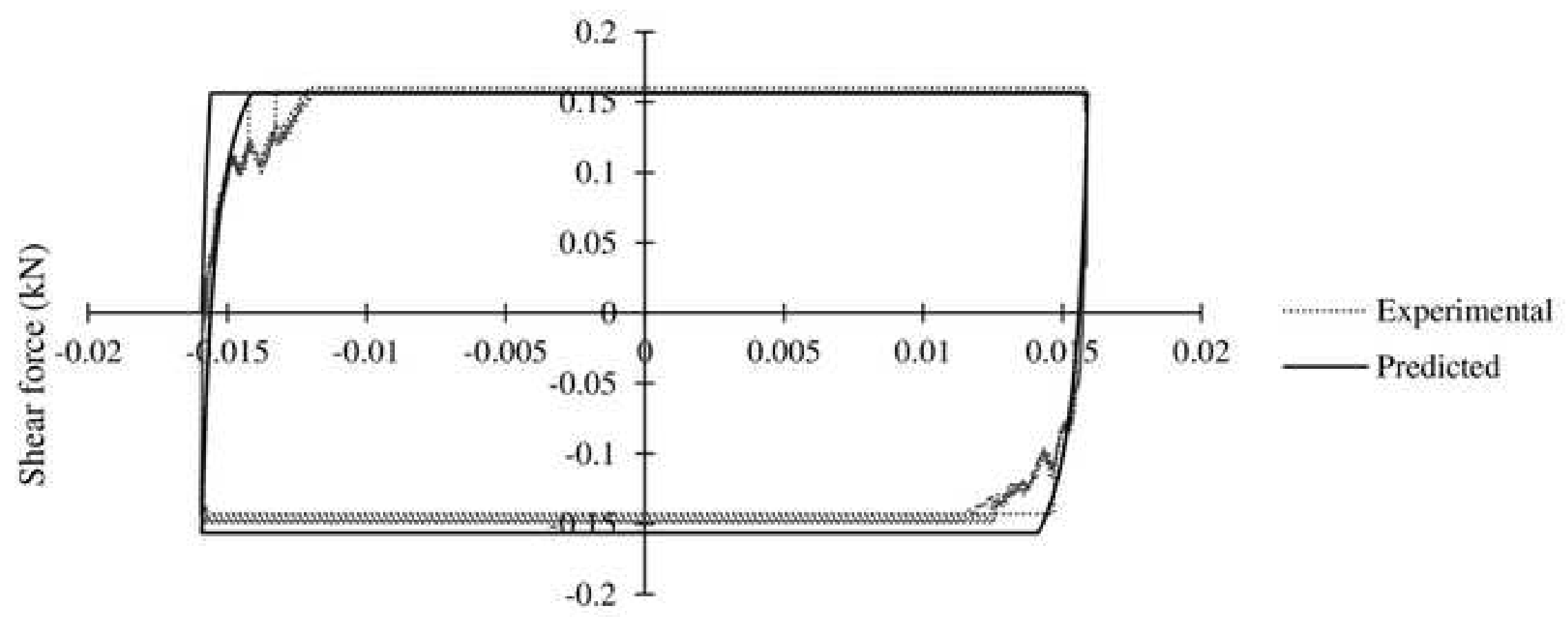

Horizontal displacement (m)

(a)

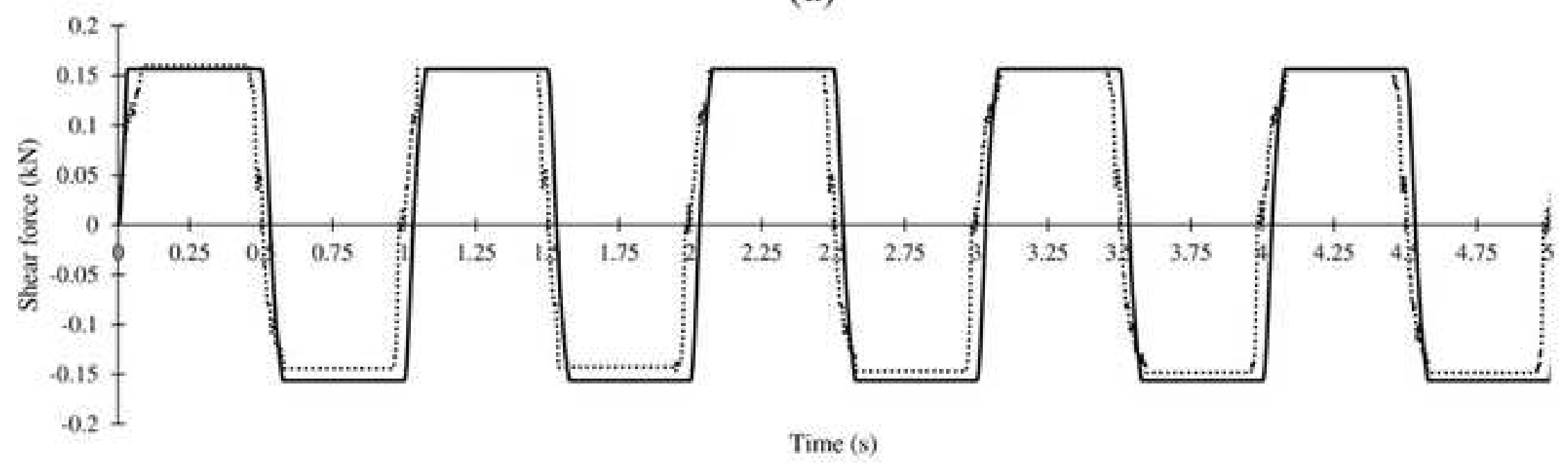

Experimental —Predicted

(b) 


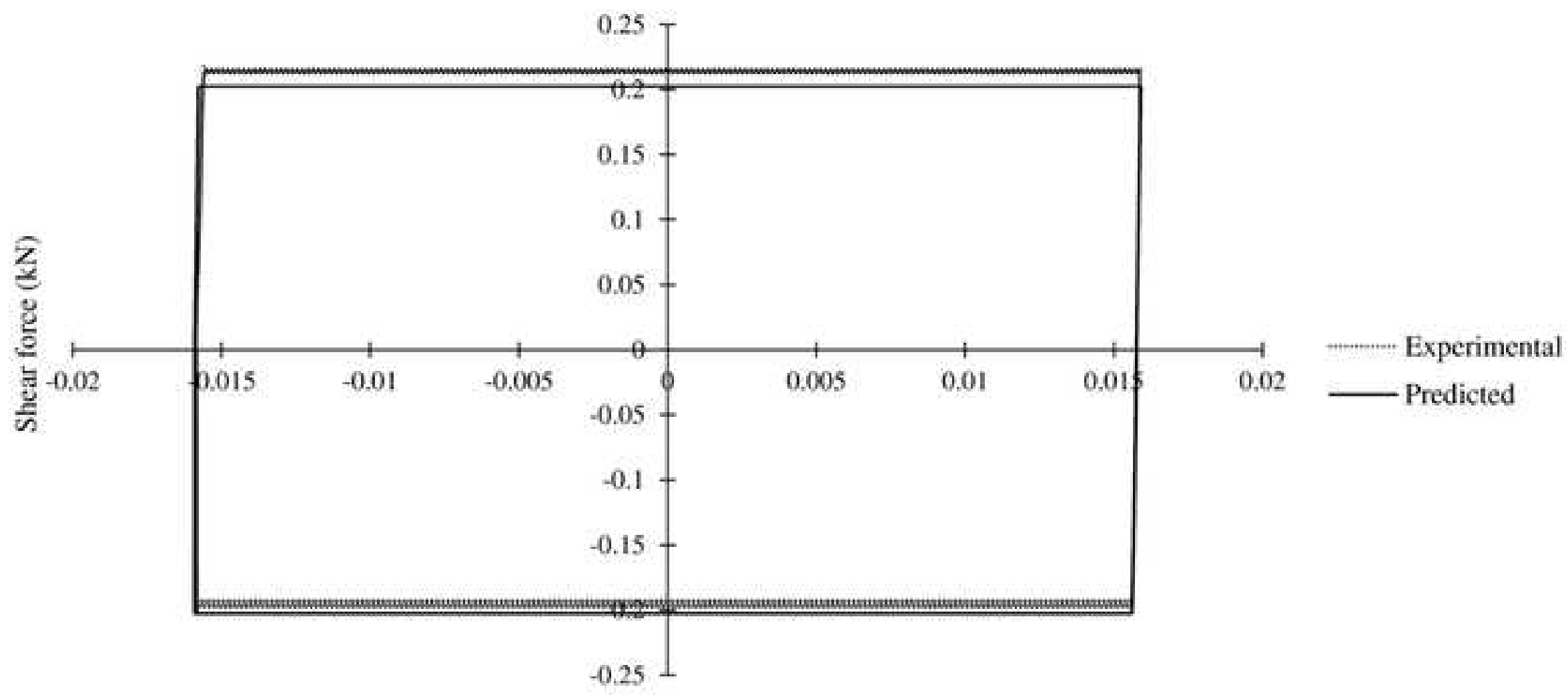

Horizontal displacement (m)

(a)

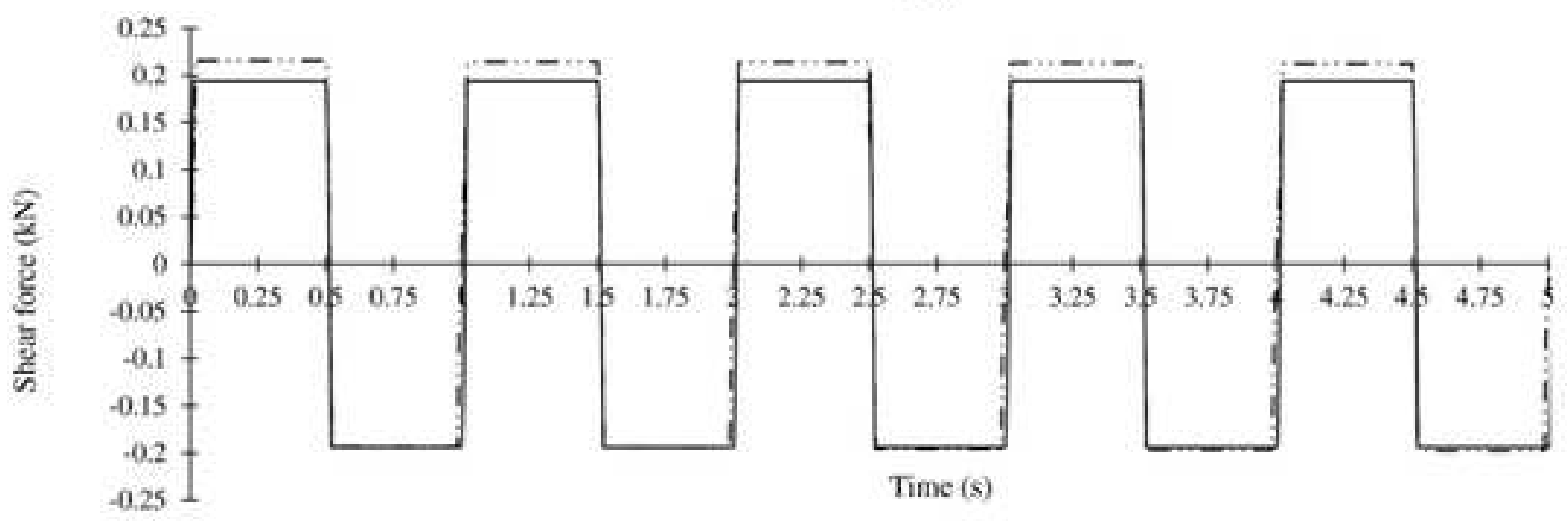

- - Experimental

- Predicted

(b) 


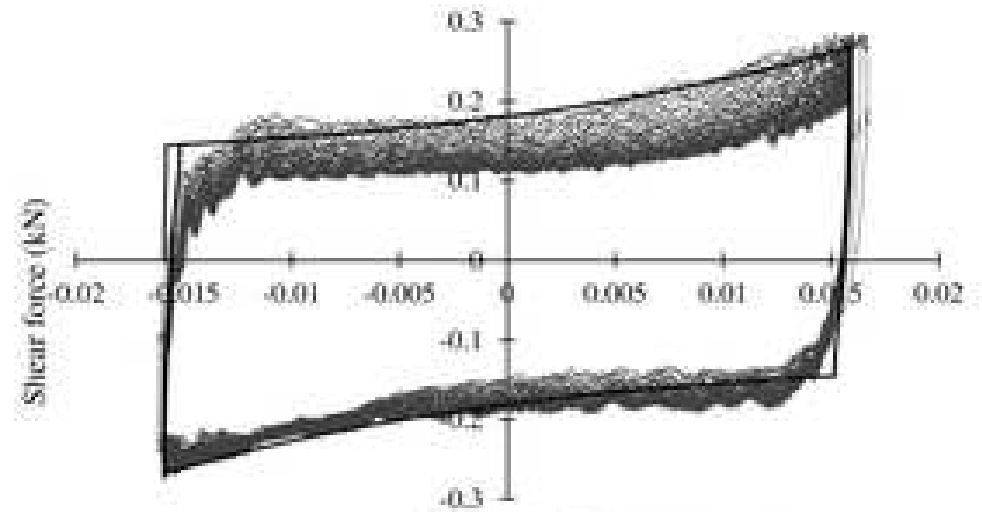

Horizontal displacement (m)

(a)
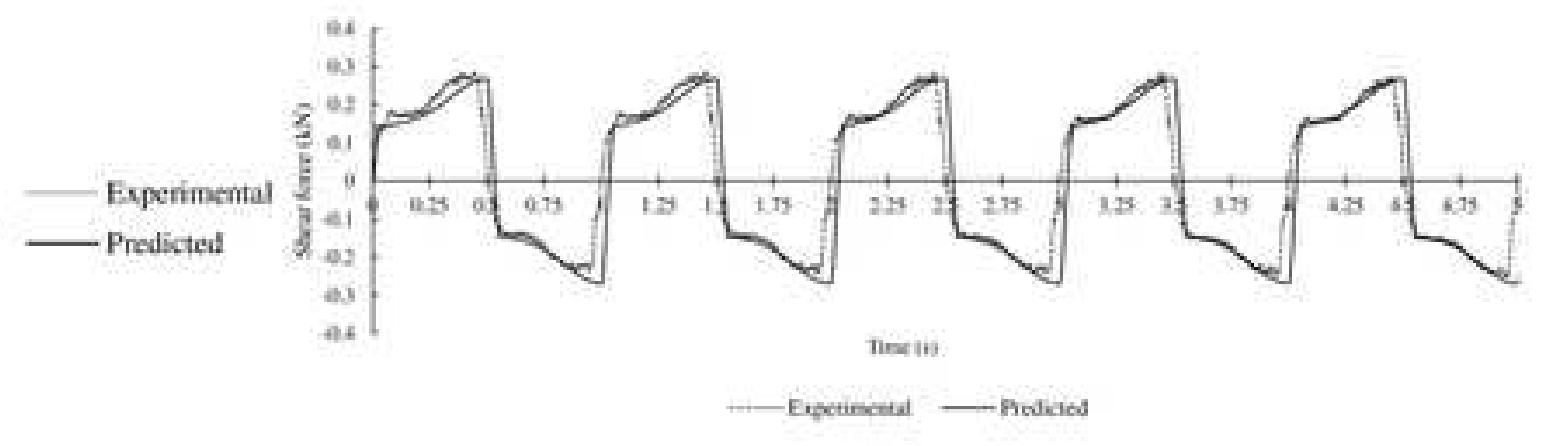

(b)

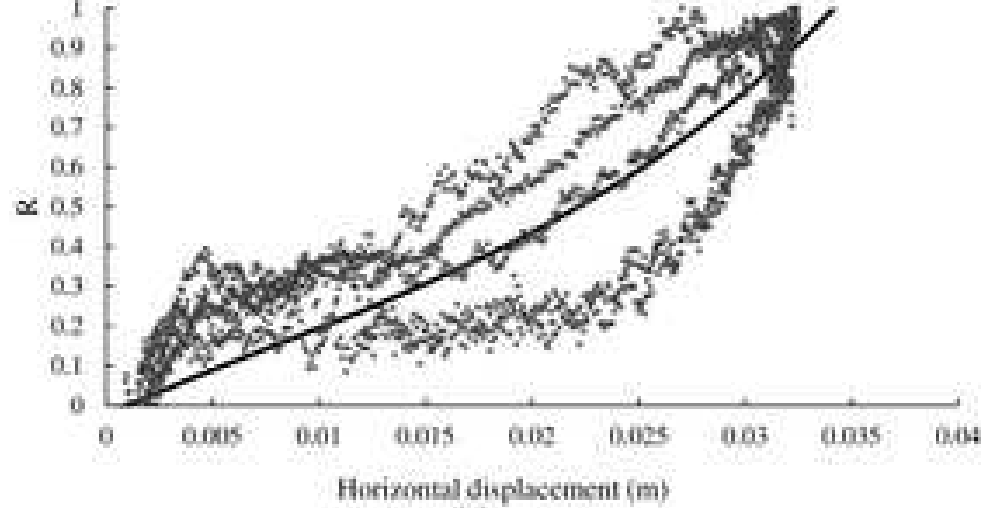

(c)
- Eeperimental

- Best fit carve 
Table 1 Properties of nonwoven needle-punched geotextile

\begin{tabular}{ll}
\hline Property & Value \\
\hline Thickness $(\mathrm{mm})$ & 1.5 \\
Mass/unit area $\left(\mathrm{g} / \mathrm{m}^{2}\right)$ & 200 \\
Wide width tensile strength (machine direction) $(\mathrm{kN} / \mathrm{m})$ & 14 \\
Wide width tensile strength (cross-machine direction) $(\mathrm{kN} / \mathrm{m})$ & 12 \\
Elongation $(\%)$ & 55 \\
Apparent opening size $\left(\mathrm{O}_{95}\right)(\mathrm{mm})$ & 0.085 \\
Permittivity $\left(\mathrm{s}^{-1}\right)$ & 1.34 \\
Flow rate $(10 \mathrm{~cm} \mathrm{head})\left(\mathrm{L} / \mathrm{m}^{2} / \mathrm{s}\right)$ & 95 \\
Permeability $(\mathrm{m} / \mathrm{s})$ & 0.0036 \\
\hline
\end{tabular}

Table 2 Properties of smooth HDPE geomembrane

\begin{tabular}{ll}
\hline Property & Value \\
\hline Thickness $(\mathrm{mm})$ & 1.5 \\
Density $\left(\mathrm{kg} / \mathrm{m}^{3}\right)$ & 940 \\
Strength at yield $(\mathrm{kN} / \mathrm{m})$ & 25 \\
Strength at break $(\mathrm{kN} / \mathrm{m})$ & 52 \\
Elongation at yield $(\%)$ & 15 \\
Elongation at break $(\%)$ & 800 \\
Puncture resistance $(\mathrm{N})$ & 400 \\
Tear resistance $(\mathrm{N})$ & 222 \\
\hline
\end{tabular}

Table 3 Results of the dynamic interface shear tests

\begin{tabular}{llll}
\hline Interface & Normal stress $(\mathbf{k P a})$ & $\begin{array}{l}\text { Maximum shear } \\
\text { force }(\mathbf{k N})\end{array}$ & $\begin{array}{l}\text { Coefficient of } \\
\text { friction (dynamic) }\end{array}$ \\
\hline \multirow{4}{*}{ GMB-GTX } & 51 & 0.15 & 0.22 \\
& 66 & 0.2 & 0.23 \\
& 97 & 0.24 & 0.22 \\
& 112 & 0.3 & 0.23 \\
& 68 & 0.36 & 0.24 \\
GMB-GMB & 88 & 0.16 & 0.24 \\
& 108 & 0.2 & 0.23 \\
& 128 & 0.28 & 0.26 \\
& 148 & 0.27 & 0.21 \\
& 51 & 0.31 & 0.21 \\
GTX-GTX & 86 & & 0.29 \\
& 91 & 0.2 & 0.31 \\
& 112 & 0.27 & 0.29 \\
& & 0.31 & 0.23 \\
\hline
\end{tabular}


Table 4 Values of parameters used for constitutive modelling of static interface behaviour

\begin{tabular}{llllllllll}
\hline Parameters & $\boldsymbol{R}_{\mathbf{f}}$ & $\boldsymbol{N}$ & $\boldsymbol{K}$ & $\boldsymbol{\operatorname { t a n }} \boldsymbol{\varphi}_{\mathbf{p}}$ & $\tan \boldsymbol{\varphi}_{\mathbf{r}}$ & $\boldsymbol{x}$ & $\boldsymbol{y}$ & $\boldsymbol{z}$ & $\boldsymbol{n}$ \\
\hline GMB-GTX & 0.85 & 0.17 & 13274 & 0.26 & 0.23 & -0.0023 & 0.9414 & 17.6 & 3.07 \\
GMB-GMB & 0.74 & 0.05 & 11218 & 0.36 & 0.31 & 0.0321 & 1.735 & 20.23 & 1.463 \\
GTX-GTX & 0.84 & 0.7 & 6957 & 0.37 & 0.37 & - & - & - & - \\
\hline
\end{tabular}

Table 5 Values of parameters used for constitutive modelling of dynamic interface behaviour

\begin{tabular}{llllllll}
\hline Parameters & $\boldsymbol{R} \mathbf{f}$ & $\boldsymbol{N}$ & $\boldsymbol{K}$ & $\boldsymbol{x}$ & $\boldsymbol{y}$ & $\boldsymbol{z}$ & $\boldsymbol{n}$ \\
\hline GMB-GTX & 0.4 & 0.6 & 1012 & - & - & - & - \\
GMB-GMB & 0.2 & 0 & 5000 & - & - & - & - \\
GTX-GTX & 0.2 & 1.37 & 1720 & 0.1511 & 55.39 & -0.85 & -1121 \\
\hline
\end{tabular}

